\section{MOLD DESIGN FOR RINGS OF EXTERNAL FIXATOR}

\begin{abstract}
MARTINA KALOVA ${ }^{1}$, FILIP TOMANEC ${ }^{2}$, SONA RUSNAKOVA ${ }^{2}$, LUKAS MANAS ${ }^{2}$, ZDENEK JONSTA ${ }^{1}$.
\end{abstract}

${ }^{1}$ Faculty of Metallurgy and Materials Engineering, VSB Technical University of Ostrava, Ostrava, Czech Republic

${ }^{2}$ Tomas Bata University in Zlin, Faculty of Technology, Department of Production Engineering, Zlin, Czech Republic.

DOI: 10.17973/MMSJ.2019_03_2018002 kaloma13@seznam.cz

This paper deals with a structural design of a mold for making a composite ring of external circular fixator used in medical applications. It also focuses on the choice of technology and material for the production of a fixator ring.

Due to the high demands on the quality, appearance, material of the product and higher series production, prepreg compression molding was chosen for this purpose. Thanks to this sophisticated production process, the high quality and accuracy of the ring can be achieved. The starting material for the production of composite components is a layer of resinsaturated fibers, abbreviated prepreg. This blank is cut on a CNC plotter and embedded into a mold for molding. The aluminium mold is provided with a separator and a filler of pores.

The result of this contribution is the design of the mold to obtain the resulting product of the required mechanical properties, functional requirements and appearance

KEYWORDS

Composite ring, external fixator, mold design, prepreg compression molding, aluminium mold

\section{INTRODUCTION}

The history of external fixators has begun centuries ago. During this time many innovations were applied, new materials and processes were discovered [Sternick 2012]. Nowadays, one of the important attributes of visible components in clinical care is appearance [Agrawal 2015]. Most of the studies show that material of external fixator is in most cases metal (see Fig. 1), which is nowadays too heavy material for medical devices [Pal 2015], [Jennison 2014], [Frydrysek 2012].

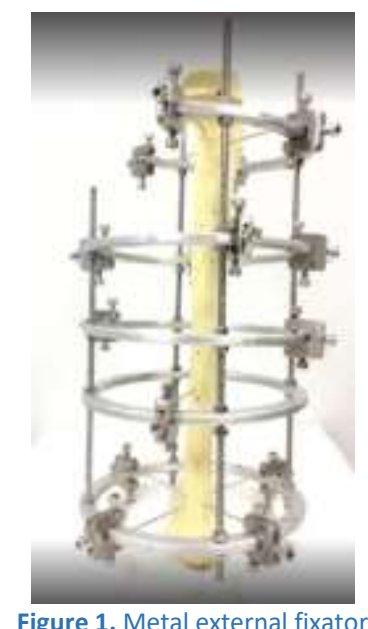

External fixation has a vital role in both provisional and definitive fracture fixation. In provisional stabilization, the surgeon must consider the impact of the fixator on the patient's care. The basic principles and techniques of external fixation should be applied to maximize the fixator's potential to promote fracture healing and minimize potential complications [Bible 2015].

For this reason, it has become a challenge to design an external fixator from a material that would meet the requirements of strength, stiffness, durability, and relief, which is beneficial to both the surgeon and the patient. The best choice was therefore composite material.

Before beginning the construction of any mold, it is necessary to devote time to considering the desired final results. The key is to think about the intention to use the finished component and what kind of mold will be needed to build it [Fibre Glast 2017]. The outward of every product depends on manufacturing operation and thus for the high quality of composite component is an excellent mold surface essential [Fibre Glast 2017], [Lu 2017].

\section{FIXATION SYSTEM-SUPPORT RINGS}

External fixation is most successful in superficial bones e.g. tibial shaft. With external fixation, pins are inserted through the skin into the bone and held in place by an external frame. The usual indications are open fractures such as a tibia fracture which requires dressings or attention to a wound or flap. It can also be used with closed fractures e.g. unstable radius fracture [Viclund 2008].

The largest parts of the external fixator are supporting rings. These perforated circles ensure the stiffness of the entire structure and also serve to clamp the other components of the fuser. The holes in the support rings are used to relieve the construction and the variable clamping of the k-wire leading into the bone.

Fig. 2 shows a detail of the support ring, which is an important part of the whole fixation apparatus.

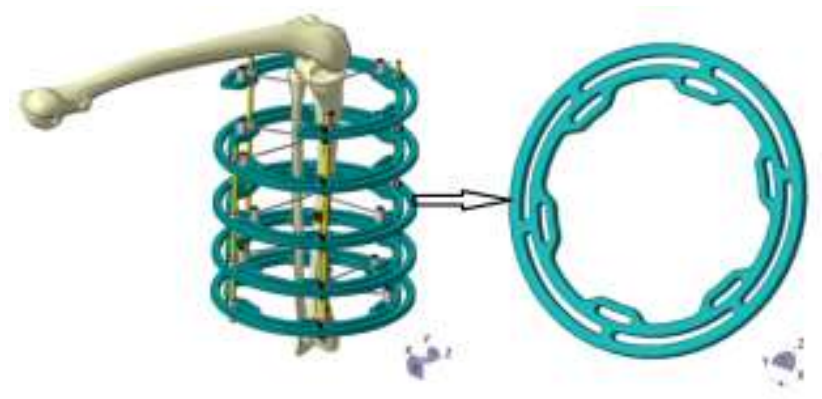

Figure 2. Detail of support ring as part of an external fixator

For the production of a composite support ring, it is first necessary to create a design and then produce a form in which composite support rings will be created.

\subsection{Technical design of support rings}

The first step was evaluated the technical design of composite ring (Fig. 3) created by software V5-6 CATIA from Dassault Systems. Catia V5-6 is 3D CAD design software for CAD / CAM / CAE applications. It can cover product design from design, through analysis and simulation to drawing documentation and NC program for own production. 

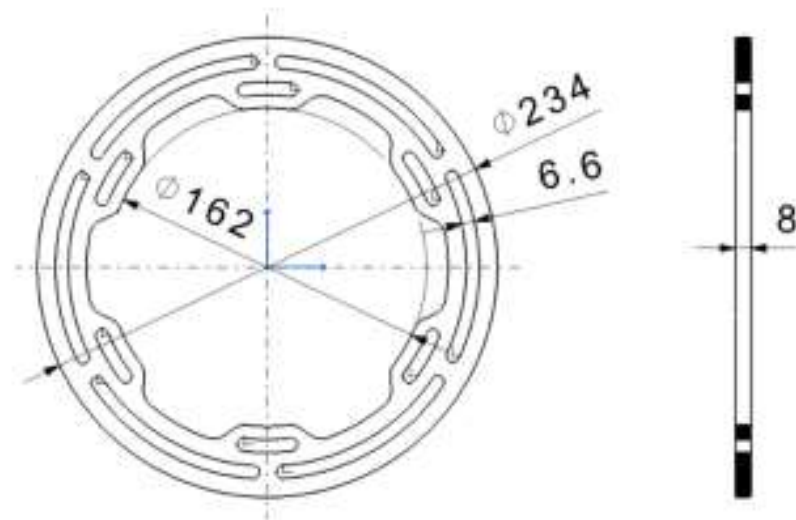

Figure 3. Design of ring of external fixator

This essential part of the external fixator ensures the rigidity and stiffness of the whole assembly and ensuring the attachment of other components together. The inner diameter $(162 \mathrm{~mm})$ of this part serves as a space for the thick part of the human limb. The external diameter of this part is $234 \mathrm{~mm}$ and the thickness is $8 \mathrm{~mm}$. The fixator assembly contains 4 pieces of the complete ring and one piece of three - quarter ring. The last ring serves as the upper ring with space for the tight part of the human limb. Rings are designed with holes serving as a space for connection rods, clamping of internal rods and as the weight reduction [Tomanec 2018]. The finished product must meet the requirements for stiffness, strength, and aesthetics.

\subsection{Design of material for support rings}

Hardly any group of polymer materials offers such extensive use as fibrous reinforced plastics, abbreviated as FRP (fiber reinforced plastics). These materials meet the requirements from simple technical applications to extreme aviation and spaceman construction [Ehrenstein 2005].

Polymer-matrix composites (PMCs) consists of a polymer resin as the matrix, with fibers as the reinforcement medium [Gupta 2015].

The design of the composite already takes into account the purpose of the final product and its stress conditions.

A carbon composite in the form of a prepreg (see Figure 4) will be used to produce finished external fixation rings. For prototype production, however, it will be enough to produce rings from cheaper material (eg glass fibers).

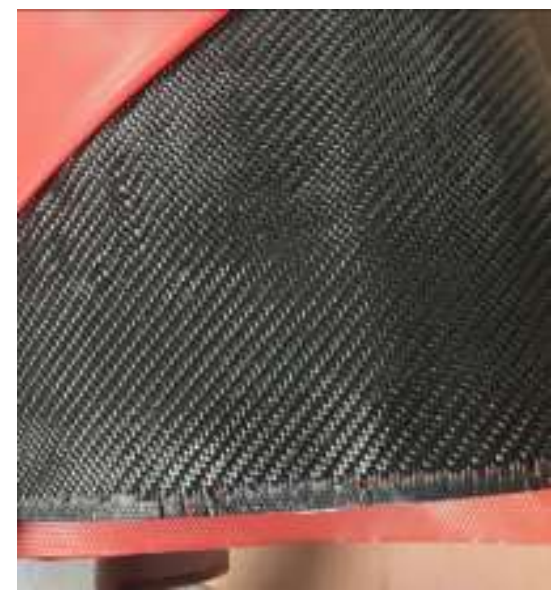

Figure 4. Carbon fiber prepreg
Carbon is a high-performance fiber material that is the most commonly used reinforcement in advanced polymer-matrix composites. Carbon fibers have the highest specific modulus and specific strength of all reinforcing fiber material and they retain their tensile modulus and high strength at elevated temperatures. At room temperature carbon fibers are not affected by moisture or a wide variety of solvents, acids, and based. These fibers exhibit a diversity of physical and mechanical characteristics, allowing composites incorporating these fibers to have specific engineered properties [Janovec 2008], [Chung 1994].

However, the fiber is almost unused due to its average in technical practice. It serves mainly as a reinforcement, which is inserted into the polymer matrix most often in the form of a fabric [Calister 2008].

In addition to reducing the weight of the whole structure, one of the other important requirements for the external fixator is its permeable by X-ray. This is a very important feature that a metal fixator does not allow. The metal part of the fixator shields the visibility of the bone fragments, and this may result in imperfect fixation. For this reason, carbon fiber-reinforced epoxy resin based polymer composite was selected for the manufacture of external rings.

Epoxy resin is one of the most versatile thermosets. Although it does not belong among the cheapest binders, it can be used practically for all processing technologies, thanks to temperature stability up to $200^{\circ} \mathrm{C}$ [Dadourek 2007], [Janovec 2008].

\subsubsection{Design of rings prototype}

Often in practice, also produces one type of product as a prototype in several ways or with different material composition. After evaluating the necessary tests, the most appropriate type of material is chosen from which the product will be produced in series.

The optimal structure of the glass fiber composite ring was prepared to evaluate the most suitable shape and arrangement of grooves by the FEM (Finite Element method) method and subjected to the load test to failure.

Before to producing the carbon rings, the rings must be subjected to mechanical testing and virtually to verify the accuracy of the simulation results. With regard to the availability and the total cost of producing the prototype of the fixator ring, a fibreglass prepreg was chosen for this purpose. Just for a large number of stress tests of the prototype rings and the fixator itself, glass fibers are an economically acceptable variant compared to other available types of composite materials [Prucha 2011].

\subsection{Technology for production of support rings}

For to obtain the product of the highest quality (dimensional accuracy, smooth surface, exact ratio of reinforcement and resin) it is advisable to use prepreg.

For the composite rings, a prepreg compression molding (PCM) method has been selected. PCM technology is based just on preimpregnated materials.

The fabric guarantees the same orientation of all threads in two main directions. The resin-coated fabric has a thickness of 1-3 $\mathrm{mm}$. The resin content is about $35 \%$. Prepregs are available in 
rolls, allowing easy handling [Legendre 2001]. Stacks of several layers of prepregs are pressed into heated metal forms and cured. The compression forces between the upper and lower forms produce good surface qualities [Štrekelj 2014], [Wulfsberg 2014].

The process is particularly suited for components with uniform wall thickness (even or dish-shaped). Also, by applying this method could be the thickness of the product around 1-10 mm [Thomas 2014].

Compared to other prepreg processes, this method has short cycle times, relatively low tool and capital costs, and lower pressure and cure temperatures than autoclaves. This method produces high-quality components [Fibre Glast 2017], [Thomas 2014], [Kursun 2016].

\subsubsection{Technology steps of PCM technology}

Demonstration of the technological process of the PCM method is schematically illustrated in Fig. 5.
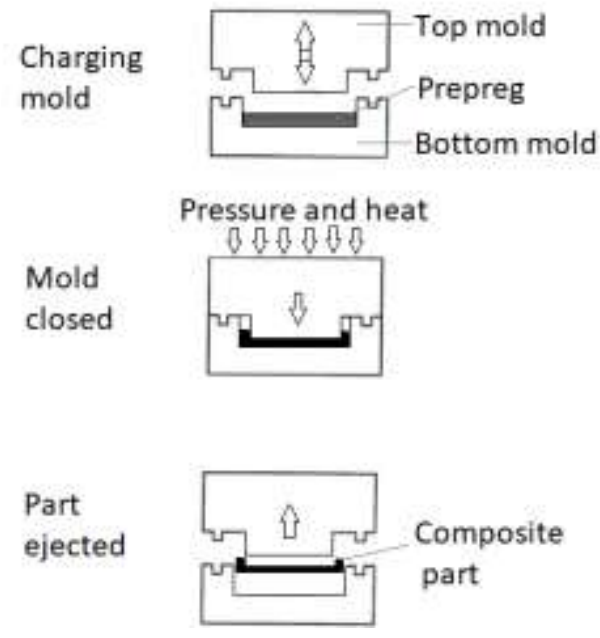

Figure 5. PCM technology

- Prepreg preparation: Prepreg defrozing, cutting, packing according to product lay-up sequence.

- Prepreg Lay-up: Lay-up of prepreg into the metal mold.

- Compression molding: Moving of bottom mold into the press, installation of the mold into the press (quick connection system) curing, removing mold from the press, cooling mold, demolding, and cleaning of mold.

- Trimming of the part: Trimming on the trimming tool using a robot.

- Assembly: Assembling (inserts or clips) and eventually bonding.

- Painting: Brushing, painting, and polishing of „nonstructural“ parts with aesthetic requirements [Wulfsberg 2014].

\section{DESIGN OF FORMS FOR PRODUCTION OF SUPPORT RINGS}

The basis for the production of essentially all composite products is the form in which the final products are still produced. Forms can be made in many ways from many different materials according to the individual requirements that this specific form must meet [Charles 2018].

Mold production is based on several criteria such as mold size, complexity and geometry, accuracy and surface quality, maximum cost limit, required durability, number of pieces produced, mold requirements, low weight for handling, dimensional stability even higher temperature, mobile design. The materials of the mold may be different. Most often they are composite or metal forms [Bures 2017], [Prucha 2011].

When plastics are pressed, a certain amount of material (prepregs) is inserted into the mold cavity. The mold is then closed, thereby generating a pressure that compresses the material and fills the mold uniformly. While the material is pressurized, it is heated to cure. This process takes place under high pressures and the molds are therefore placed in presses [Strong 2008].

The advantage of the metal form is also that the manufacturing phase of the model is avoided because the mold can be produced immediately by machining on a CNC plotter according to the $3 \mathrm{D}$ design in the design software.

Based on this evaluation was chosen a method of composite production in the closed aluminium mold. The technical design of the construction of the two-sided aluminium mold for the production of the outer fixing ring can be seen in Fig. 6 . In this investigation, the mold for a composite product was constructed in designing software CATIA V5-6 from Dassault Systemes. Ring molding was designed to ISO $2768 \mathrm{mK}$ accuracy and ISO 8015 tolerance.

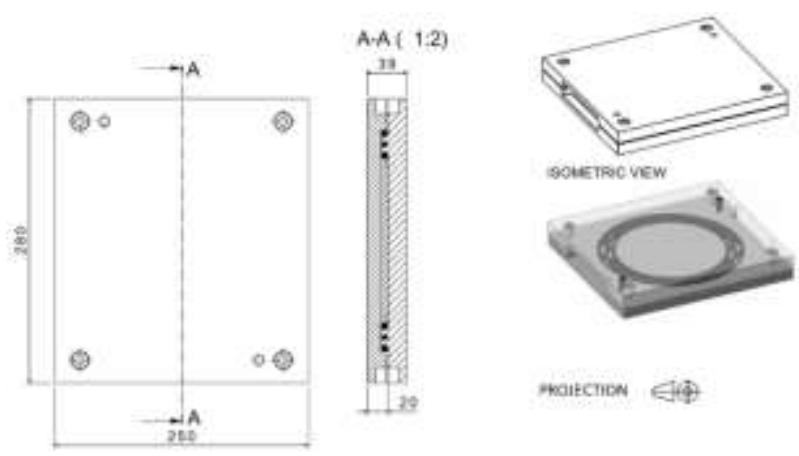

Figure 6. Drawing documentation of the aluminum mold

Due to its good polishability and machinability, Aluminium is suitable for molds for high-quality products (visible parts). Aluminium molds are mainly used for smaller products produced in larger series.

The design of the mold, core and block for the ring of the external fixator is based on the options and size of the school press. An aluminium cuboid of $250 \mathrm{~mm} \times 280 \mathrm{~mm} \times 39 \mathrm{~mm}$ is chosen as the primary blank. The mold, the design of which is shown in Fig. 7, is designed for easy handling in molding and for the smallest production demands.

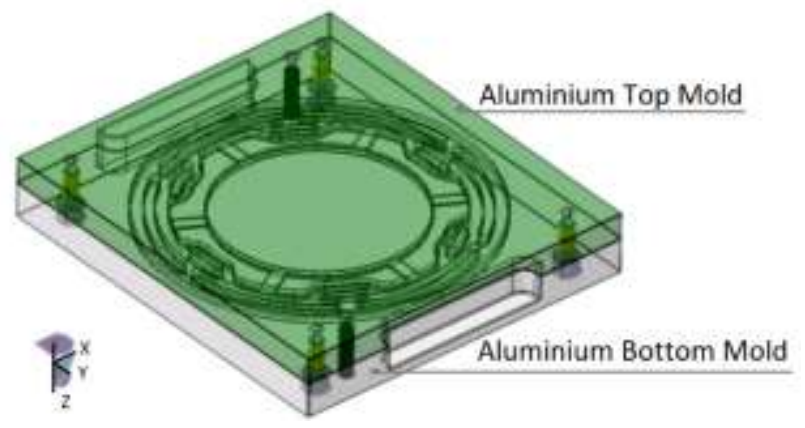

Figure 7. Aluminium Mold 
Aluminium alloy EN AW 5083 [AlMg4.5Mn0.7] was selected for the mold. It is a naturally hard material, unstretchable, chemically stable with good workability and polishability. Tensile strength is about $270-345 \mathrm{MPa}$, yield strength $0.2 \%$ Proof is $115-$ $200 \mathrm{MPa}$. Aluminium 5083 is very versatile in its technological properties. It is well weldable, anodized, and corrosion resistant. This alloy can be milling and drilling smoothly because the material does not have much resistance [Klichova 2016], [Atlassteels 2013].

Alloy 5083 is a non-heat-treatable $4 \frac{1}{2} \%$ magnesium, $0.15 \%$ chromium, $0.7 \%$ manganese alloy commonly available in flatrolled plate from a range of producing mills. Alloy 5083 is best known as a plate for ship building, unfired welded pressure vessels, rail and other vehicles, various structural applications that make use of the high strength. The alloy is also produced as extruded seamless tube and other extrusions and as forgings. Excellent in a wide range of atmospheric environments, in food processing and architectural applications. The magnesium content is more than $3 \frac{1}{2} \% \mathrm{Mg}$, so this alloy can be susceptible to stress corrosion cracking, which limits its application temperature to below $65^{\circ} \mathrm{C}$ and also limits the amount of cold work to $1 / 4$ Hard.

Alloy 5083 is not hardenable by heat treatment. It can be significantly hardened by cold work (eg. by cold rolling) and various " $\mathrm{H}$ " tempers are produced.

The alloy spontaneously age-softens at room temperature immediately after cold work but will eventually reach a stable condition; all flat rolled mill products are supplied with stable properties [Atlassteels 2013].

It was necessary to design the aluminium form in more detail because the mold consists of two parts. On the first bottom plate, as can be seen in Fig. 8 , at another point, was mold cavity created by the removal of material from this plate.

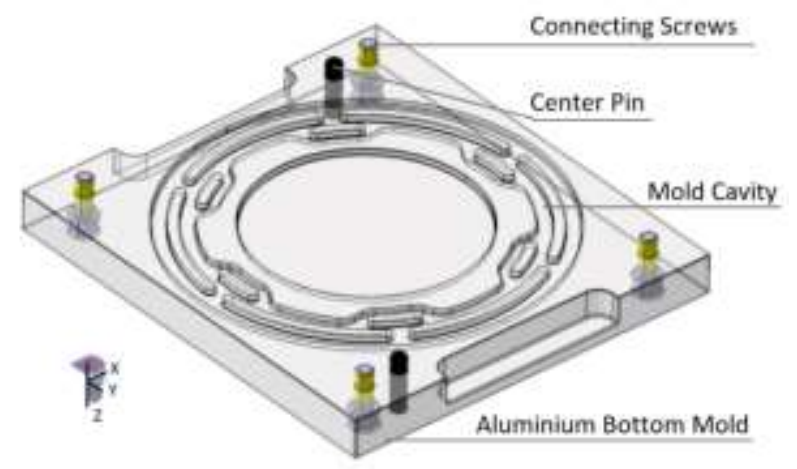

Figure 8. Aluminium Bottom Mold

A second top plate of the mold assembly (see Fig. 9) was then proposed.

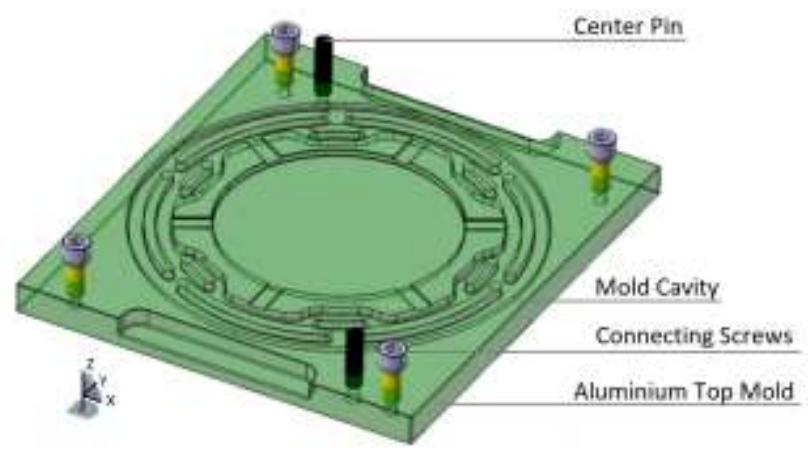

Figure 9. Aluminium Top Mold
The core of the mold was designed to produce many more holes on each ring, reducing weight and also covering the location of $\mathrm{K}$-wires. This part does not contain any holes for the ejection system because the end product is manually removed.

Parts of the mold in contact with composite are finely machined for the superior surface of the product. Both plates are equipped with an opening for easy handling, connected together by the screw and one another are centred by pins.

The centering of the mold is ensured by a pair of pins with a diameter of $12 \mathrm{~mm}$. For transport or storage, screw holes are placed on the mold. Single grooved holes for hexagon bolts are milled for the molder. In the block, the holes are provided with a M10 screw thread.

The mold is loaded with reinforcement and resin before closing and tightening. The excess resin is removed, the cavities are reduced and both sides of the part have a smooth surface.

The disadvantage of the aluminium mold is the low scratch resistance of the surface, which mainly occurs when the mold part is removed after curing. For serial production it is necessary to provide the mold with a suitable surface treatment.

The finished aluminium mold can be seen in Fig. 10.

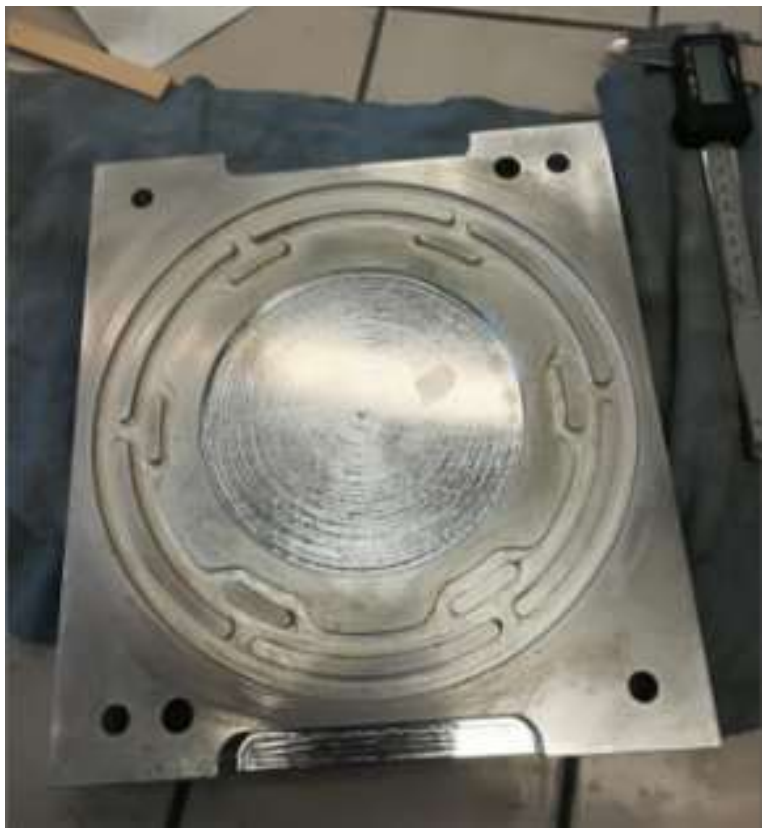

Figure 10. Finished aluminium mold

Molds for composite parts require high accuracy and surface quality because the composite accurately copies the shape. After machining the aluminium mold, the surface is ground and polished, but the pore filler must be applied before the first use of the mold to fill the micropores and scratches on the surface of the mold, the so-called separator. Mold must be properly separation and the separator polished, otherwise there is a risk of mold damage and destruction due to mutual bonding. Waxes or semi-permanent solvent based coatings are used. The selection of the separator depends on the choice of the product matrix, the curing temperature and the surface roughness of the mold [Pancl 2010]. Frekote 770-NC separator was used for this particular mold.

In addition, the surface was provided with a gelcoat layer to provide a protective layer and a better mold surface. Gelcoat is selected according to the resin used, in this case EG 100-T epoxy 
gelcoat was used. Epoxy gelcoats have a higher hardness and are therefore more resistant to abrasion. It can be applied both spraying and painting. It creates a smooth viewing layer and does not require further editing after removing the mold. The surface is created directly in form, which means both efficiency and financial savings. Hardener $\mathrm{H} 100$ was used to harden the gelcoat. The thickness of the gelcoat used as the topcoat is about $0.1 \mathrm{~mm}$.

\subsubsection{Production of fibreglass rings prototype}

Layer parts are cut from prepregs on CNC plotters. Prepreg is made of glass fabric $280 \mathrm{~g} / \mathrm{m}^{2}$ with $46 \%$ epoxy resin FT102. The total prepreg weight is $519 \mathrm{~g} / \mathrm{m}^{2}+/-2 \%$. The cure temperature is $125^{\circ} \mathrm{C}$ [Havel Composites 2018]. The epoxy matrix contained in the prepreg has a limited lifetime and therefore the prepregs are stored at temperatures below freezing, usually at $-18 \stackrel{\circ}{ } \mathrm{C}$. Prior to use, the prepregs are tempered one day in a sealed container to room temperature, and then the specific parts are cut on a CNC cutting plotter vacuum table. Prepreg cuts for the visible parts must be provided with a foil on both sides because a slightly sticky prepreg sticks to dirt that cannot be molded into the products. The CNC Cutting Plot Program ensures that the specified fiber orientation of the fabric is maintained [Pancl 2010]. Fig. 11 shows a carved layer of a fibreglass prepreg provided with a protective foil.

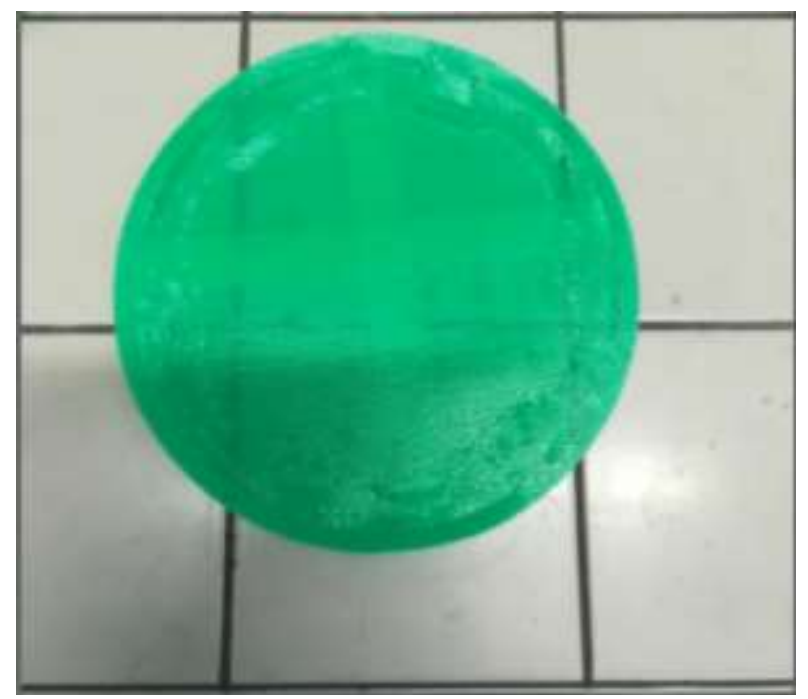

Figure 11. Layer of fibreglass prepreg

Perforations in the prepreg layer (see Fig. 12) are cut according to the drawing documentation exactly so that the individual reinforcement layers can be laid in the mold. Threeteen layers of glass prepreg were used on one support ring of an external fixator.

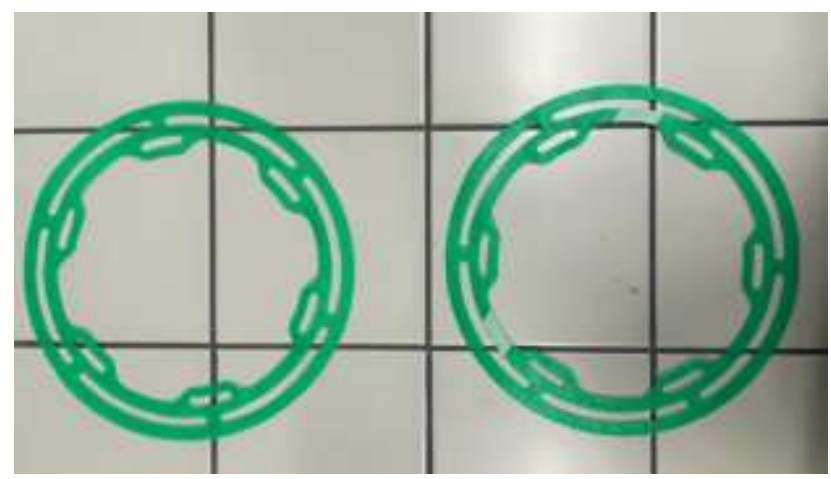

Figure 12. Perforated layers of fiberglass prepreg
Cutting holes in prepreg layers before composing rings will simplify work, because machining of composite parts brings many pitfalls. When machining composites, many material damage occurs due to their appearance, mechanisms of origin and distortion other than metallic materials. The most common type of damage is delamination. In general, drills with the smallest length of a transverse blade, positive geometry and a sharp cutting edge are best suited to achieving higher quality machined surfaces. The most suitable are fine-grained sintered carbides and polycrystalline diamond. An alternative is, for example, laser cutting [Sedlacek 2007].

Forming layers into a mold must be done in a room with a controlled environment. In the clean room, constant values of relative humidity, temperature and maximum dust content are maintained. The composition of the first layer is the most critical. The improperly deposited layer is irreversibly deformed by press and then unusable [Pancl 2010].

For the manufacture of prepreg composite laboratory press heated by MITAS, a.s. Zlín (see Fig. 13) was used. The press includes electrically heated plates and a hydraulic jack to create a pressing pressure. Power consumption is $2400 \mathrm{~W}$, maximum temperature $200^{\circ} \mathrm{C}$ and clamping force 5 tons.

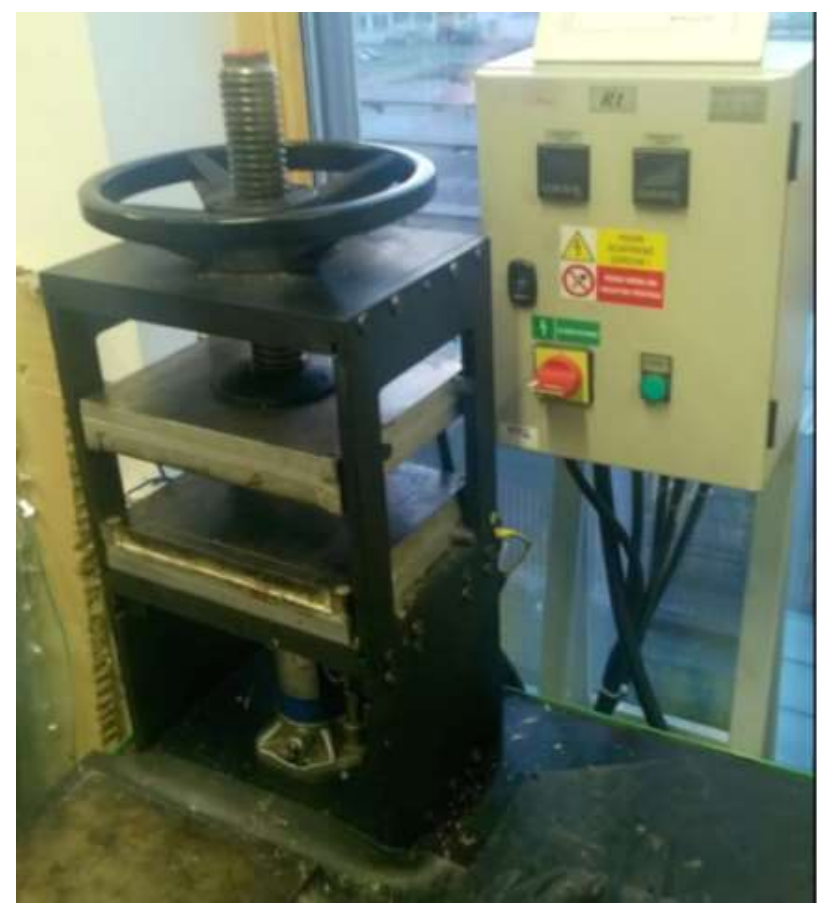

Figure 13. The laboratory press

\section{CONCLUSIONS}

The aim of the paper was to propose a mold for the production of composite rings. A variant of a two-sided "closed" aluminium mold was chosen, which is ideal for producing precision parts. The design of the aluminium mold was created in 3D CATIA software. Then the mold was made according to this drawing documentation.

The mold has been designed from an aluminium alloy 5083 . This material is then milled mildly and the surfaces that form the resulting surface of the part are subsequently folded manually. The rings was made using PCM technology. Compared to other prepreg processes, this method has short cycle times, relatively low tool and capital costs, and lower pressure and cure 
temperatures than autoclaves. This method produces highquality components

The fiberglass prepreg, which is available and cheap, was used to make the ring prototype. 13 layers of prepreg was used on one composite ring. The individual layers were pre-cut on the CNC plotter including perforations so that the layers could be laid in the mold.

The mold is loaded with reinforcement and resin before closing and tightening. The excess resin is removed, the cavities are reduced and both sides of the part have a smooth surface.

The theoretical basis of this article is to serve as a basis for the prototype production of the two-sided closed aluminium mold, the production of the composite ring of the external fixator and the external fixator itself in a new, lightweight composite form.

Now the aluminium mold and fiberglass rings are finished and fiberglass rings are tested by failure tests. The results from the failure test are compared with the results of the Finite Element Method. The proposed design can reduce the weight of the external fixator and therefore simplify the surgeon's work, improve patient comfort and overall fracture treatment. In practice, instead of using fiberglass, it is planned to use carbon fiber composites on rings. The results for fiberglass rings are recalculated for carbon material. Carbon is permeable to X-rays, a very desirable property in medical practice.

Another part of the research will be devoted to combining the material so that the external fixator is interesting both aesthetically and cost-effectively while fulfilling the required mechanical properties and preserving its functionality.

\section{ACKNOWLEDGMENTS}

This paper was prepared with a contribution of the projects "SP2018/70 Study of relationships between the technology and processing of advanced materials, their structural characteristics and utility properties" and "SP2018/60 Specific research in the metallurgical, materials and process engineering" and with the financial support of the internal grant of TBU in Zlin No. IGA/FT/2018/004 funded from the resources of specific university research.

\section{REFERENCES}

[Agrawal 2015] Agrawal, H. K., et al. Cosmetic arm lengthening with monorail fixator. SD, 2015, Vol.18, pp 170-174.

[Atlassteels 2013] Atlas Steel. Aluminium Alloy Data Sheet 5083, 2013, Melbourn [online]. [13/10/2018]. Available from http://www.atlassteels.com.au/

[Bible 2015] Bible, J. E., et al. External Fixation: Principles and Applications. JAAOS - Journal of the American Academy of Orthopaedic Surgeons, 2015, Vol.23, No.11, pp 683-690, doi: 10.5435/JAAOS-D-14-00281

[Bures 2017] Bures, T. Composite materials, VSTE Budejovice, 2018, Ceske Budejovice [online]. [01/10/2018]. Available from http://player.slideplayer.cz/21/6936677/\#

[Calister 2008] Calister, W. D. Jr. and Rethwish, D. G. Fundamentals of materials science and engineering an integrated approach, $3^{\text {rd }}$ ed. USA: Wiley, 2008. ISBN 978-0-47012537-3.
[Charles 2018] Charles-composite production. 2018, Praha [online]. [01/10/2018]. Available from http://www.charles.cz/formy/

[Chung 1994] Chung, D. D. Carbon fiber composites. Newton: Butterworth-Heinemann, 1994. ISBN 0-7506-9169-7.

[Dadourek 2007] Dadourek, K. Composite materials-types and their use. Liberec: Technical University in Liberec, 2007. ISBN 978-80-7372-279-1.

[Ehrenstein 2005] Ehrestein, W. G. Polymer composite materials. Praha: Scientia, 2005. ISBN 978-80-554-0505-6

[Fibre Glast 2017] Fibre Glast. Mold construction, Fibre glast developments corp., 2017, Brookville [online]. 12/09/2018. Available from https://www.fibreglast.com/product.

[Frydrysek 2012] Frydrysek, K., et al. Design of External Fixators used in Traumatology and Orthopaedics - Treatment of Fractures of Pelvis and its Acetabulu. Procedia Engineering, 2012, Vol.48, pp 164-173.

[Gupta 2015] Gupta, K. M. Engineering materials. New York: CRC Press, 2015. ISBN 978-1-4822-5797-7.

[Havel Composites 2018] Havel Composites. Fibreglass Prepreg, 2018, Praslavice [online]. [09/11/2018]. Available from http://www.havel-composites.com/shop/0-home/912-Skelnyprepreg-280gmspan-stylefont-size-11pxsup2supspan--46epoxy-pryskyrice-PR-FB1304-2801270-FT10246.html?calcqty $=20 \#$

[Janovec 2008] Janovec, J., Cejp, J. and Steidl, L. Perspective materials. Praha: CVUT Praha, 2008. ISBN 978-80-01-04167-3

[Jennison 2014] Jennison, T., McNally, M. and Pandit, $H$. Prevention of infection in external fixator pin sites. Acta Biomaterialia, 2014, Vol.10, No.2, pp 595-603.

[Klichova 2016] Klichova, D., Klich, J. and Gurkova, L. Study of quality of nine aluminium alloys surfaces created using abrasiv waterjet. MM Science Journal, 2016, pp 892-895, doi: 10.17973/MMSJ.2016_03_201608

[Kursun 2016] Kursun, A. and Topal, E. Investigation of hole effects on the critical buckling load of laminated composite plates. Mater. Technol., 2016, Vol.50, No.1, doi:10.17222/mit.2014.164

[Legendre 2001] Legendre, A. Carbon materials: From black ceramic to carbon fiber. Praha: Informatorium, 2001. ISBN 8086073-82-3.

[Lu 2017] Lu, J., et al. Surface polishing and modification of $3 \mathrm{Cr} 2 \mathrm{Mo}$ mold steel by electron beam irradiation. SD - Vacuum, 2017.

[Miller 2017] Miller, C. Prepreg Laminating vs. Wet Lay-up, Hub Pages, 2017, USA [online]. [01/10/2018]. Available from http://player.slideplayer.cz/21/6936677/\#

[Pal 2015] Pal, C. P., et al. Comparative study of the results of compound tibial shaft fractures treated by llizarov ring fixators and limb reconstruction system fixators. Chinese Journal of Traumatology, 2015, Vol.18, No.6, pp 347-351. 
[Pancl 2017] Pancl, O., et al. Production of carbon fiberreinforced polycarbonate parts. Praha: MM industrial spectrum, 2010.

[Prucha 2011] Prucha, P., et al. Comparison of technologies for the production of curing agents from composite materials. Praha: Transfer-VZLU, a. s., 2011. ISSN 1801-9315.

[Sedlacek 2007] Sedlacek, J. Problems in machining of composite materials. Praha: MM industrial spectrum, 2007.

[Sternick 2012] Sternick, M. B., et al. Relationship between rigidity of external fixator and number of pins: Computer analysis using finite elements. Revista Brasilia de Ortopedia, 2012, Vol. 47 , pp. $646-650$

[Strekelj 2014] Strekelj, N., et al. Characterization of a polymermatrix composite support beam. Materials and technology, 2014, Vol.48, No.3, pp 429-432.

[Strong 2008] Strong, A. B., Fundamentals of composites manufacturing. Michigan: Society of Manufacturing Engineers, 2008, pp 620. ISBN 0-978-087263-854-5.

[Thomas 2014] Thomas, S., et al. Polymer Composites. Biocomposites, 2014, Vol.3, pp 582.

\section{CONTACTS}

Ing. Martina Kalova

VŠB-Technical University in Ostrava, Faculty of Metallurgy and Materials Engineering,

17.listopadu 15/2172, Ostrava, 708 33, Czech Republic

Tel.: 00420608132560, e-mail: kaloma13@seznam.cz

Ing. Filip Tomanec

Tomas Bata University in Zlin, Faculty of Technology, Department of Production Engineering, Vavreckova 275, Zlín, 760 01, Czech Republic.

e-mail: solvetech@solvetech.cz

doc. Ing. Sona Rusnakova, Ph.D.

Tomas Bata University in Zlin, Faculty of Technology, Department of Production Engineering, Vavreckova 275, Zlín, 760 01, Czech Republic.

e-mail: rusnakova@utb.cz,http://www.utb.cz/ft

Ing. Lukas Manas

Tomas Bata University in Zlin, Faculty of Technology, Department of Production Engineering, Vavreckova 275, Zlin, 760 01, Czech Republic. e-mail: Imanas@utb.cz, http://www.utb.cz/ft

prof. Ing. Zdenek Jonsta, CSc.

VŠB-Technical University in Ostrava, Faculty of Metallurgy and Materials Engineering, 17.listopadu 15/2172, Ostrava, 708 33, Czech Republic e-mail: zdenek.jonsta@vsb.cz manec 2018] Tomanec, F., et al. Optimization of the Material of External Fixator with FEM Simulation. Materials Science Forum, 2018, Vol. 919, pp 275-281.

[Viclund 2008] Viclund, A. External fixators. University Stellenbosh, 2008, South Africa [online]. [01/06/2018] http://www0.sun.ac.za/ortho/webctortho/general/exfix/exfix/ html

[Wulfsberg 2014] Wulfsberg, J., et al. Combination of carbon fibre sheet moulding compound and prepreg compression moulding in aerospace industry. Procedia Engineering, 2014, Vol.3, pp 1601-1607. 